\title{
DESAFIOS URBANOS À DEMOCRATIZAÇÃO DO ACESSO ÀS OPORTUNIDADES EDUCACIONAIS NAS METRÓPOLES BRASILEIRAS*
}

\author{
Luiz Cesar de Queiroz Ribeiro ${ }^{1}$ \\ Mariane Campelo Koslinski ${ }^{2}$ \\ Carolina Zuccarelli ${ }^{3}$ \\ Ana Carolina Christovãó ${ }^{4}$
}

\begin{abstract}
RESUMO: O presente artigo sistematiza o progresso da pesquisa sobre os padróes de organização social do território das metrópoles brasileiras e seus impactos nos mecanismos de reproduçáo das desigualdades educacionais entre crianças e jovens. Ele tem como base os resultados de um grande número de investigaçóes empíricas realizadas pelo grupo de pesquisa multidisciplinar "Educaçáo e Cidade", integrante do Instituto Nacional de Pesquisa eTecnologia (INCT) — "Observatório das Metrópoles" - CNPq/FAPERJ. Além de apresentar o estado da arte sobre o conhecimento referente à relação entre os processos de segmentação e segregação residencial e as desigualdades de acesso à estrutura de oportunidades educacionais, o artigo também propóe a reflexão sobre a necessidade da consideração do território urbano como dimensão transversal das políticas de educação e da cidade.
\end{abstract}

Palavras-chave: Regiôes metropolitanas. Segregação residencial. Desigualdades urbanas. Desigualdades educacionais.

\section{URBAN CHALLENGES TO EDUCATIONAL OPPORTUNITIES ACCESS IN BRAZILIAN METROPOLIS}

ABSTRACT: The present article systematizes the progress of the research on the patterns of social organization of the Brazilian Metropolis territory and its impacts on mechanisms of educational inequalities reproduction among children and adolescents/youth. It relies on results of a great number of

\footnotetext{
*Agradecemos a colaboraçáo de Marcelo Gomes Ribeiro (IPPUR/UFRJ) para a discussão e elaboração dos gráficos que apresentam a relação entre as dimensóes do Índice de bem-estar urbano e as tipologias sócio-ocupacionais.

${ }^{1}$ Universidade Federal do Rio de Janeiro (UFRJ), Instituto de Pesquisa e Planejamento Urbano e Regional (IPPUR) - Rio de Janeiro (RJ), Brasil. E-mail: lcqribeiro@gmail.com

${ }^{2}$ UFRJ, Faculdade de Educação - Rio de Janeiro (RJ), Brasil. E-mail: mckoslinski@gmail.com

${ }^{3}$ UFRJ, Instituto de Filosofia e Ciências Sociais (IFCS) - Rio de Janeiro (RJ), Brasil.

E-mail: carol_zucca@yahoo.com.br

${ }^{4}$ UFRJ, Faculdade de Educação - Rio de Janeiro (RJ), Brasil.

E-mail: anacarolinachristovao@yahoo.com.br

DOI: 10.1590/ES0101-73302016157093
} 
empirical investigations carried out by the multidisciplinary research group, "Education and the City", part of the National Institute of Research and Technology (INCT) — "Observatory of the Metropolis" — CNPq/FAPERJ. Besides presenting the state of the art of the research on the relationship between the processes of residential segregation and segmentation and inequalities of access to educational structure of opportunities, the article also proposes considerations on the need of taking the urban territory into account as a transversal dimension of educational and city policies.

Keywords: Metropolitan regions. Residential segregation. Urban inequalities. Educational inequalities.

\section{DÉFIS URBAINS À LA DÉMOCRATISATION DE L'ACCÈS AUX OPPORTUNITÉS ÉDUCATIONNELLES DANS LES VILLES BRÉSILIENNES}

RESUMÉ: Cet article systématise les progrès de la recherche sur les schémas d'organisation sociale du territoire des villes brésiliennes et leurs impacts sur les mécanismes de reproduction des inégalités éducationnelles parmi les enfants et les jeunes. Il est basé sur les résultats d'un grand nombre d'études empiriques menées par le groupe de recherche multidisciplinaire "Educação e Cidade" (Éducation et Ville), membre de l'Institut National de Recherche et de Technologie (INCT) — "Observatório das Metrópoles" (Observatoire des Métropoles) - CNPq/FAPERJ. En plus de présenter l'état de l'art sur les connaissances relatives parmi les processus de segmentation et de ségrégation résidentielle et les inégalités d'accès à la structure d'opportunités éducationnelles, l'article propose également une réflexion sur la nécessité d'un examen du territoire urbain en tant qu'une dimension transversale des politiques de l' éducation et de la ville.

Mots-clés: Régions métropolitaines. Ségrégation résidentielle. Inégalités urbaines. Inégalités éducationnelles.

\section{Introdução}

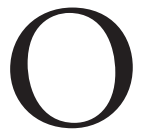

presente trabalho discute recentes mudanças na realidade urbana brasileira e suas possíveis implicaçóes para o acesso a oportunidades educacionais a partir de diversos estudos desenvolvidos pela rede de pesquisa Observatório das Metrópoles ${ }^{1}$. Dessa forma, pretende contribuir e aprofundar as discussóes realizadas no V Seminário da Educação Brasileira sobre mudanças estruturais e sociais no contexto brasileiro (em especial sobre as cidades e as metrópoles) e o direito à educação pública de qualidade.

Desde suas origens, na década de 1990, o Observatório das Metrópoles se preocupou com o fenômeno da segregação urbana, mais especificamente com a concentração territorial dos segmentos vulneráveis da população, e seu potencial 
de desencadeamento de mecanismos de reprodução da pobreza e das desigualdades sociais, compreendidos como ameaças aos princípios de equidade social. No contexto brasileiro, o processo de urbanização foi simultâneo à metropolização da rede urbana. As metrópoles concentram as forças produtivas do país e, ao mesmo tempo, apesar da diminuição da pressão demográfica do passado, vivemos uma questão social nelas: o que a economia gera de promessa de melhorias do bem-estar pela expansão do emprego e da renda, a cidade rouba e transforma em mal-estar urbano.

Isso também pode ser mencionado a respeito de certas políticas públicas que vêm conhecendo inflexôes importantes nos últimos 15 anos em termos de democratização do acesso a serviços públicos e à estrutura de oportunidades. Por exemplo, a política habitacional que passou a atingir as camadas baixas do déficit habitacional, diante do encarecimento do preço do solo aliado à lógica empresarial, está provendo acesso à moradia, mas não à cidade. Outro exemplo é a política educacional, sua promessa de universalização do acesso ao ensino básico e de melhoria da qualidade e da equidade. Muitos dos bloqueios a que esses três desafios sejam alcançados provêm da metrópole, das suas condições materiais, sociais e ambientais (RIBEIRO; SOUZA; RODRIGUES, 2010).

Assim, estudos anteriores (RIBEIRO, 2010) discutem a combinação de três processos de transformação em curso na sociedade urbana brasileira, cujo epicentro está nas metrópoles: transformaçôes e a crescente segmentação do mercado urbano de trabalho, mudanças do âmbito familiar e sua fragilizaçáo como espaço de socialização e de redistribuiçáo de recursos, e os processos de segmentação e segregação residencial. Diversos estudos realizados no Observatório das Metrópoles partem da hipótese inicial de que processos socioespaciais, como a diferenciação, a segmentação e a segregação, em curso nas metrópoles, têm grande importância para a compreensão de mecanismos de exclusão e de integração. Esses processos socioespaciais teriam impacto no padrão de sociabilidade das relaçóes de vizinhança. De um lado, tais relaçóes seriam marcadas por isolamento social e restriçôes do capital social; de outro, por um baixo grau de exposição a ativos que permitam superar situaçóes de exclusão caracterizadas, por exemplo, pelo acesso desigual ao bem estar-urbano.

A partir de meados dos anos 2000, o Observatório das Metrópoles passou a investigar, também, as desigualdades das chances de escolarização de crianças e jovens de grandes cidades, na perspectiva da democratização do acesso à educaçáo de qualidade e do enfrentamento aos efeitos perversos das desigualdades de origem sobre as trajetórias individuais (RIBEIRO; KAZTMAN, 2008). Mesmo que pensar a relação entre cidade e educação não seja complemente estranho à agenda de pesquisa dos estudos urbanos (WILSON, 1987; JENCKS; MAYER, 1990, SMALL; NEWMAN, 2001; ELLEN; TURNER, 1997), pouco sabíamos sobre essa relação no contexto brasileiro. Assim, o Observatório das Metrópoles, 
em parceria com pesquisadores de outros laboratórios de pesquisa e universidades, desenvolveu o projeto de pesquisa Observatório Educação e Cidade ${ }^{2}$. Este tomou como hipótese central a possibilidade de a divisão socioespacial da cidade produzir efeitos sobre os resultados educacionais, de modo semelhante como o fazem as características da escola e da família. Em um primeiro momento, as seguintes questóes nortearam os estudos desenvolvidos por esse projeto:

1. A segregação residencial característica dos aglomerados urbanos metropolitanos exerce impacto sobre resultados escolares, controlados pelo efeito da família e da escola?

2. Que mecanismos do efeito vizinhança podem ser observados no contexto brasileiro?

3. Os diferentes modelos de segregação dessas cidades implicam diferentes impactos sobre resultados escolares? Já o segundo projeto, Observatório Educação e Cidade ${ }^{3}$, tinha entre seus objetivos compreender a relação entre segregação residencial, geografia de oportunidades educacionais e segregação escolar.

O presente trabalho pretende regatar diversos estudos desenvolvidos pelo Observatório das Metrópoles para, num primeiro momento, fazer uma discussão sobre as mudanças recentes no contexto urbano/metropolitano no Brasil. O foco principal são os processos de segmentação e segregação residencial, e suas relações com a sociabilidade e o acesso ao bem-estar urbano. Em seguida, discute a relevância dessas mudanças para desigualdades educacionais a partir de trabalhos desenvolvidos no âmbito dos projetos Observatório Educação e Cidade. De um lado, traça um panorama das evidências sobre a relação entre as desigualdades urbanas, em especial a segregação residencial e/ou efeito vizinhança sobre resultados educacionais e acesso à educação de qualidade no contexto brasileiro. Para tanto, discute evidências encontradas por estudos que utilizaram bases secundárias e metodologia quantitativa. De outro lado, a partir de estudos qualitativos em áreas segregadas, discute os processos e mecanismos por meio dos quais a segmentação e a segregação residencial impactam resultados escolares e/ou acesso à educação pública de qualidade. Por fim, discute a implicação da falta de planejamento intersetorial no contexto brasileiro para o agravamento da relação entre os processos de segregação residencial e as desigualdades educacionais.

\section{Transformações urbanas: tendências recentes}

O padrão de desenvolvimento capitalista no Brasil que se convencionou chamar de substituição de importações foi responsável por um processo intenso 
de mudança estrutural no país. Dirigido e financiado pelo Estado em associação com capitais nacionais e estrangeiros, esse padrão vigorou entre as décadas de 1930 e 1980, e transformou o perfil do país de agrário em eminentemente urbano. No entanto, urbanização nunca foi sinônimo de melhoria de vida, nem mesmo no auge do desenvolvimentismo. O crescimento econômico do período aconteceu de forma concentrada, o que contribuiu para manter sempre em níveis muito baixos a renda do trabalho urbano. Além disso, o padrão de inclusão escolar dos que migraram do campo para a cidade foi muito lento, ainda que tenha havido mobilidade educacional de uma geração para outra, especialmente porque partiu de patamares muito baixos de escolaridade geral. A reprodução social, diferente de outros países, nunca se colocou como custo da acumulação do capital e, com isso, a função de gerir os riscos da reprodução e da descoesão social acabou a cargo das famílias e comunidades. Essa forma de assegurar o bem-estar social, conhecida como famílistico-mercantil ${ }^{4}$, é uma das responsáveis pelo que Ribeiro (2013) chamou de metropolizaçáo da questão social, isto é, a relaçáo entre vulnerabilidade social e as tendências à segmentação e segregação residencial nas grandes cidades.

O período de 1980/2010 conforma um longo processo de transformação da ordem urbana, especialmente por conta da expansão da participação do mercado na organização da cidade e do crescimento das forças liberais-internacionalizantes, que tornaram as cidades brasileiras atrativas para capitais que buscavam alternativas à crise de acumulação global (RIBEIRO, 2013). As mudanças macrossociais e macroeconômicas do período, de acordo com o autor, tornaram mais relevantes a compreensão dos efeitos da organização social do território metropolitano justamente porque os processos socioespaciais em curso nas metrópoles têm grande importância na compreensão dos mecanismos de produção/reprodução das desigualdades sociais.

A organização social do território das metrópoles é marcada pelos processos de diferenciação, segmentação e segregação residencial, de acordo com distinção formulada por Kaztman (2001)5. Diferenciação diz respeito à expressão espacial da crescente especialização de tarefas por conta do aumento da divisão social do trabalho, que gera diferenças nos atributos de duas ou mais categorias sociais de recursos. A diferenciação se transforma em segmentação residencial quando barreiras materiais condicionam a distribuição dos grupos e classes sociais no território, como os decorrentes da distribuição desigual das condiçôes de transportes urbanos e da formação do preço do solo urbano. Já o conceito de segregação soma aos dois últimos processos barreiras institucionais que criam distâncias e hierarquias sociais entre grupos e classes sociais. De acordo com Ribeiro (2003), a organização social do território das metrópoles brasileiras está fortemente baseada na autossegregação das classes superiores proprietárias do capital econômico e cultural como resultado da luta desigual pelo controle dos recursos urbanos - serviços, equipamentos e oportunidades - e do prestígio social conferido pela localização. 
Um dos principais trabalhos produzidos sobre os impactos da segregação urbana sobre as oportunidades individuais foi o estudo de Wilson (1987) no qual o autor explicita a hipótese de que viver em uma vizinhança com alta concentração de pobreza afeta negativamente as chances de vida de uma pessoa, independentemente do nível de pobreza do indivíduo ${ }^{6}$. Seguindo a mesma hipótese em contextos urbanos latino-americanos, Kaztman (2001) destaca que a alta concentração territorial da pobreza acarreta, por um lado, uma debilidade dos vínculos com o mercado de trabalho, atingindo os trabalhadores de baixa qualificação, e, por outro, um progressivo isolamento dos pobres urbanos do restante da sociedade. Aliada a esses fatos, tem-se a segmentação do trabalho, da educação e a segmentaçáo residencial. O autor afirma que a segmentação do trabalho diz respeito à redução da interação social entre os trabalhadores mais qualificados e os menos qualificados. Já a segmentaçáo da educação é vinculada ao enfraquecimento do processo de constituiçấo de redes de estudantes de composição social heterogênea que, em sua análise, contribuiria para a equidade na distribuição de ativos de capital social. As barreiras existentes na interaçáo entre os diferentes grupos sociais comprometem a capacidade reivindicatória dos segmentos mais fragilizados, o que tem sérios impactos na distribuição dos equipamentos urbanos como, por exemplo, a escola.

Uma importante questão que se coloca é saber de que maneira o processo de segregação urbana agravou o quadro de isolamento social e, consequentemente, o acesso ao "bem-estar" das regiōes metropolitanas do Brasil. Para dar conta dessa dimensão, em 2013, o Observatório das Metrópoles elaborou o Índice de Desenvolvimento Urbano (IBEU) ${ }^{8}$, uma medida que leva em conta o bem-estar do cidadáo promovido pelo mercado e pelo Estado no que diz respeito às condiçôes coletivas de vida no ambiente construído da cidade, no bairro ou vizinhança. Essa concepção de bem-estar urbano se afasta da concepção utilitarista decorrente do consumo individual para considerar o plano coletivo do ponto de vista das condiçóes materiais que a cidade deve oferecer às pessoas.

É nesse sentido que a dimensão coletiva da moradia é analisada a partir das condiçóes de vida e desenvolvimento náo apenas do indivíduo, mas de todos os que estão ao seu redor ou em sua vizinhança. $\mathrm{O}$ pressuposto é de que os vários aspectos que circundam a moradia contribuem para o modo como se dá a reprodução social coletivamente na cidade. Assim, é possível dizer que as condiçôes urbanas expressam a maneira pela qual os processos de estruturação urbana ocorrem sobre a forma de acessar a moradia e em que condições. Nessa dimensão do IBEU, destaca-se a região metropolitana de Florianópolis com as melhores condiçóes habitacionais e as regiốes metropolitanas de Manaus e Belém com as piores condiçōes habitacionais.

De maneira geral, o índice indica particularidades importantes das condições de bem-estar urbano, expressa nas diferenças regionais entre as regióes Norte e Nordeste de um lado, e as regiôes Sul, Sudeste e Centro-Oeste de outro. Indica também que as metrópoles precisam de níveis e necessidades distintas de 
bem-estar urbano, entendendo que suas condiçôes internas também são diversas em todas as dimensóes.

$\mathrm{O}$ atendimento de serviços coletivos urbanos (água, lixo, esgoto e energia) foi o índice com a média mais elevada das dimensóes do IBEU. Ainda assim, as regióes metropolitanas de Belém e Manaus apresentaram índice abaixo da média geral, destacando a extrema desigualdade existente entre as regiōes metropolitanas. A distribuição desigual desses ativos reflete as chances desiguais de oportunidades dos diferentes grupos sociais.

Outra dimensão importante - a mobilidade urbana — assume características específicas do ponto de vista metropolitano, notoriamente porque as pessoas que vivem em espaços urbanos estão fortemente sujeitas às condiçôes de deslocamento cotidiano. A capacidade de deslocamento, entre outras coisas, depende da infraestrutura existente na cidade, daí a importância em assumir que as condiçóes de mobilidade oferecidas pelo sistema urbano podem contribuir para diferenças de bem-estar urbano na cidade e entre os grupos sociais nela existentes. O impacto causado pelas dificuldades de deslocamento no acesso ao emprego e à renda muitas vezes se deve à concentraçáo da oferta de trabalho nas áreas centrais e ao crescimento da populaçáo moradora de periferias distantes. Estudo desenvolvido por Ribeiro; Souza; Rodrigues (2010) na regiáo metropolitana do Rio de Janeiro mostra, por exemplo, que moradores de áreas com diferenças de mobilidade urbana podem perder até $22,8 \%$ do seu potencial de renda do trabalho, considerando o nível de escolaridade.

Para analisar a organizaçáo social do território metropolitano, uma importante ferramenta metodológica que denominamos análise social do território, cuja variável central é a categoria sócio-ocupacional ${ }^{9}$, permite a compreensão dos padrôes de distanciamento e hierarquia que agregam e segregam os grupos e as classes sociais existentes nas metrópoles. Os estudos desenvolvidos pelo Observatório das Metrópoles com base nessa metodologia vêm gerando evidências robustas sobre o papel dos padrôes de segregação residencial na reprodução das desigualdades de condições urbanas de vida e de oportunidades. Por exemplo, em Ribeiro, Souza e Rodrigues (2010) e Ribeiro e Chetry (2015) foi demonstrado para a metrópole do Rio de Janeiro como a hierarquia socioespacial corresponde a fortes desigualdades em termos de bem-estar urbano. Fato representado pelos Gráficos 1 a 3 .

No que concerne à dimensão oportunidade, diversos estudos vêm demonstrando também os efeitos da segregação residencial na manutenção das desigualdades entre os indivíduos em termos de êxito educacional (JENCKS; MAYER, 1990; ELLEN; TURNER, 1997; SMALL; NEWMAN, 2001; RIBEIRO; KOSLINSKI, 2010; KOSLINSKI; ALVES; LANGE, 2013). Sobre esse ponto hoje parece não haver dúvida na literatura, porém permanece em discussão a compreensão dos mecanismos que explicam esses efeitos. Nesse sentido, merece destaque a revisão 


\section{Gráfico 1}

Índice de Bem-Estar Urbano - Condições habitacionais urbanas por tipologia sócio-ocupacional - Região Metropolitana do Rio de Janeiro.

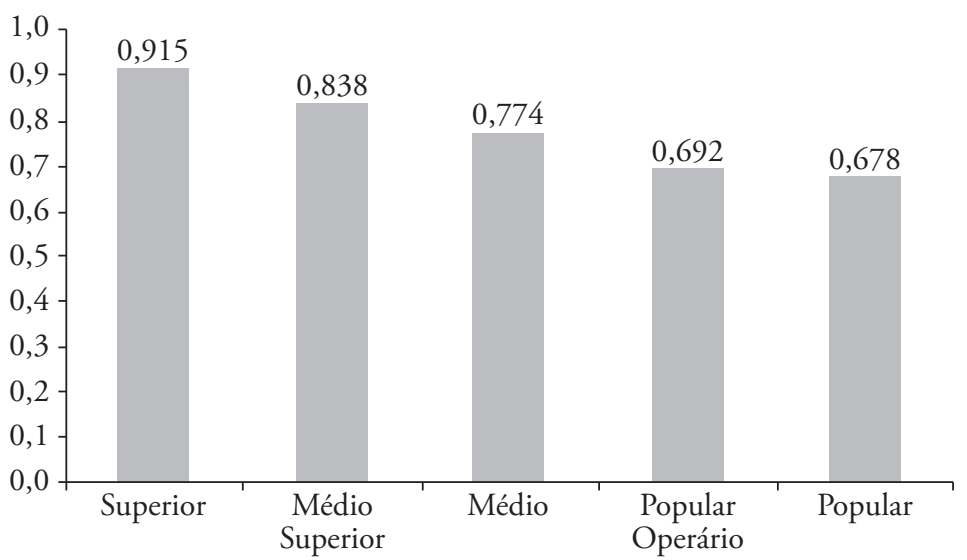

Fonte: Observatório das Metrópoles, 2015.

\section{Gráfico 2}

Índice de Bem-Estar Urbano - Atendimento de serviços coletivos urbanos por tipologia sócio-ocupacional - Região Metropolitana do Rio de Janeiro.

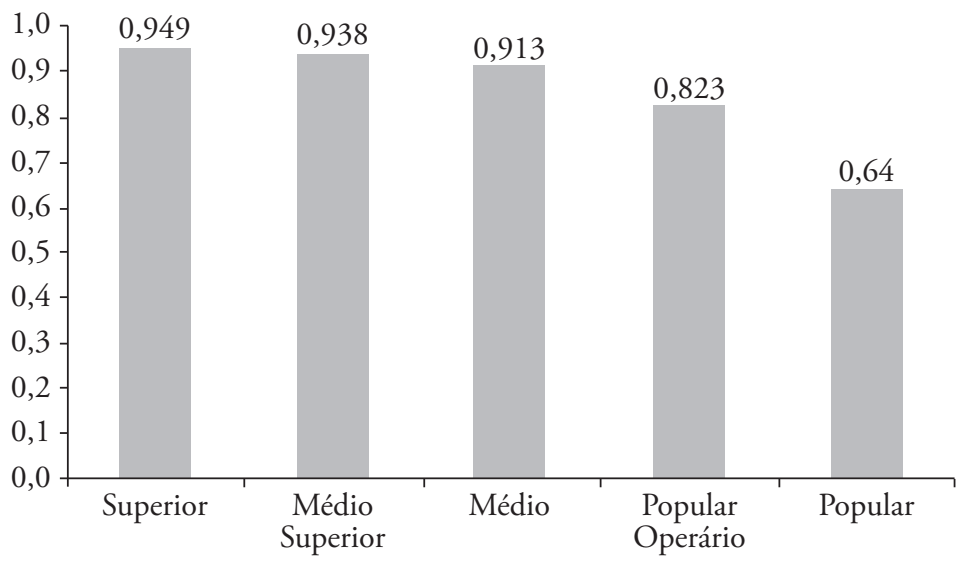

Fonte: Observatório das Metrópoles, 2015.

e a categorização dos estudos sobre o que a literatura americana chama de efeito vizinhança desenvolvidas por Small e Newman (2001). Os autores discutem a influência do trabalho seminal The Truly Disadvantaged de Wilson (1987), sobre a subsequente produção a respeito do tema da pobreza urbana. Small e Newman 


\section{Gráfico 3 \\ Índice de Bem-Estar Urbano - Mobilidade urbana por tipologia sócio-ocupacional - Regiâo Metropolitana do Rio de Janeiro.}

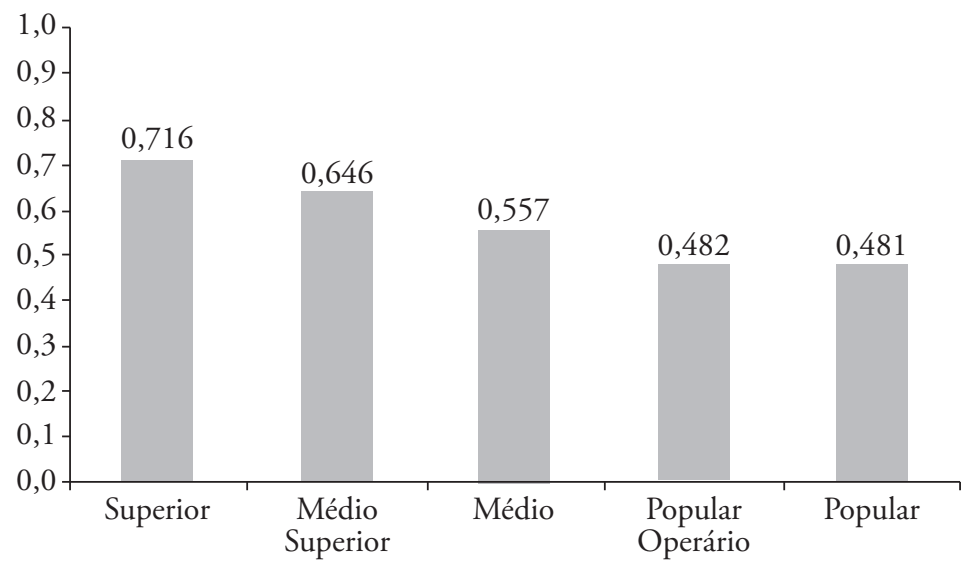

Fonte: Observatório das Metrópoles, 2015.

(2001) dividem os mecanismos a partir dos quais o efeito vizinhança afeta as oportunidades individuais em duas categorias abrangentes:

1. mecanismos de socialização;

2. mecanismos instrumentais.

A primeira categoria agrupa explicaçóes relacionadas a processos de socialização que se estabelecem em um bairro/vizinhança. Tais explicaçōes partem do pressuposto de que os indivíduos seriam receptores passivos de processos ou forças irresistíveis de socialização que conformariam certos padróes de comportamento. Por exemplo, podemos citar efeito pares ou de modelos de papel social (WILSON, 1987; JENCK; MAYERS, 1990), cujos efeitos negativos afetariam principalmente crianças e adolescentes residentes em bairros/vizinhanças caracterizadas por concentração de pobreza.

Por sua vez, a segunda categoria, caracterizada por mecanismos instrumentais, reúne explicação de como a agência dos indivíduos é limitada por certas condiçôes das vizinhanças. Tais condições, de um lado, incluem o apartamento de redes sociais que contribuem, por exemplo, para acessar oportunidades de emprego. A restrição de redes sociais nos ajuda também a pensar um efeito sobre a capacidade das famílias de acessarem oportunidades educacionais, em especial no momento de escolha e acesso a estabelecimentos escolares ${ }^{10}$. De outro, abrangem modelos que defendem que a segregação residencial levaria à distribuiçẫo desigual 
de recursos institucionais, como escolas, áreas de lazer, assistência social e, portanto, áreas com concentração de pobreza sofreriam, seja com a privação de tais equipamentos ou com equipamentos de pior qualidade. No contexto brasileiro, podemos estender as privaçóes para o acesso a certos serviços básicos, como abastecimento de água, coleta de lixo e saneamento, como também para a mobilidade urbana e condições de moradia.

Como discutido acima, o acesso a serviços e condiçóes que fazem parte do bem-estar urbano varia entre as metrópoles, e observamos grandes desigualdades de acesso dentro delas. Num contexto de fragmentação e desarticulação das políticas públicas, o desafio federativo que se coloca é como dar conta da diversidade de realidades urbanas num modelo de administração do território que escamoteia o planejamento intersetorial. No campo da educação, a incorporação da dimensão espacial na construção de indicadores educacionais amplia a possibilidade de compreender os mecanismos produtores de desigualdades de oportunidades em diversas escalas e, ao mesmo tempo, possibilita o levantamento de subsídios para as açóes de intervenção governamental.

A seguir, discutimos alguns estudos que incorporaram tal dimensão para compreender a relação entre a segregação residencial e as oportunidades educacionais.

\section{Segregação residencial e desigualdades educacionais: algumas evidências sobre o Brasil}

Desde o primeiro projeto Observatório Educação e Cidade, desenvolvemos uma gama de estudos quantitativos que investigaram, seja a partir de análises mais descritivas ou da estimação de modelos de regressão multinível, a relação entre certas características das regióes metropolitanas brasileiras, em especial a segregação residencial, e diversos desfechos/resultados escolares. Tanto a segregação residencial, quanto os desfechos escolares foram medidos de diversas formas para mensurar, bem como para trazer pistas sobre, os mecanismos que explicariam as relaçóes entre características da vizinhança e trajetória e/ou desempenho escolar.

Mesmo que a maioria dos estudos sobre esse tema, realizados no Observatório das Metrópoles, tenha se concentrado na região metropolitana e/ou no município do Rio de Janeiro, algumas evidências foram observadas para o conjunto das regióes metropolitanas brasileiras. Por exemplo, o estudo realizado por Ribeiro (2010) buscou identificar a relação entre risco de estar em situação de vulnerabilidade social e certas tendências e características da segmentação e segregação residencial nas regióes metropolitanas brasileiras ${ }^{11}$.

Os padróes de segmentação e segregação residencial característicos das metrópoles brasileiras foram captados, em primeiro lugar, a partir de uma variável que caracterizou o contexto social dos bairros/vizinhanças ${ }^{12}$. $\mathrm{O}$ indicador de contexto social local ou da vizinhança foi elaborado a partir do percentual de pessoas que moravam em 
domicílios cujo responsável exerce ocupaçóes consideradas como estáveis, protegidas e bem remuneradas em cada área de ponderação do IBGE. As áreas de ponderação do IBGE foram utilizadas como proxy dos bairros/ou vizinhanças e foram classificadas em três grupos ${ }^{13}$ : baixa, média e superior (de acordo com a concentração de indivíduos com inserção no mercado de trabalho em posiçóes de alto/baixo status). Os contextos locais/ ou dos bairros também foram caracterizados de acordo com a integração dos municípios às regiōes metropolitanas e as regióes do país em que os bairros estavam localizados ${ }^{14}$.

O estudo observou a relação entre as características dos bairros e as condições de vulnerabilidade de crianças, adolescentes e jovens residentes nas regióes metropolitanas. Trazemos aqui um resumo das evidências para duas situaçóes de risco mais relacionadas à distribuição de oportunidades educacionais nas metrópoles brasileiras:

- risco 1: indica crianças/adolescentes entre 4 e 14 anos fora da creche ou escola, ou em situação de atraso escolar;

- risco 2: indica jovens de 15 a 24 anos que não trabalham, não estudam, nem procuram emprego. As análises controlaram o impacto do contexto local dos bairros por características das crianças e jovens e

\section{Gráfico 4}

Risco estimado de estar em situação de vulnerabilidade.

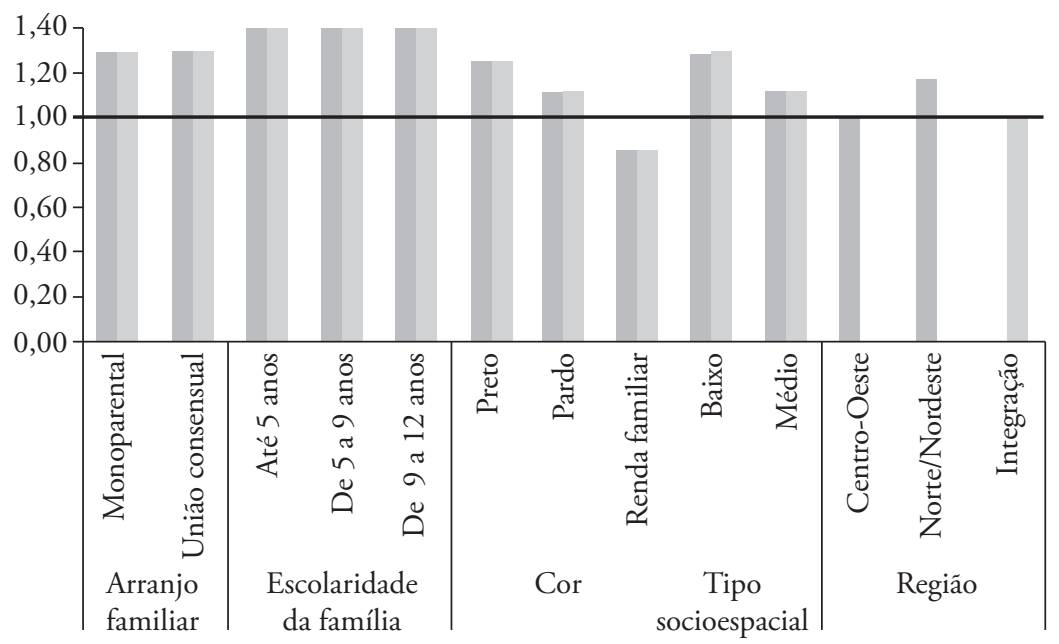

Risco $1 \quad$ Risco 2

As categorias "uniäo estávelllegalizada", "mais de 12 anos", "branco", "médio", "Sudeste" foram as categorias de referência para as variáveis arranjo familiar, escolaridade da familia, cor, tipo socioespacial

e regiäo, respectivamente. O gráfico apresenta o risco relativo associado a cada uma das variáveis independentes inseridas no modelo final das regressöes logísticas multinivel estimando os risco 1 e 2 de vulnerabilidade. Os gráficos apresentam resultados somente para os coeficientes estimados pelas regressöes que apresentaram significância estatística $(p \leq 0,10)$.

Fonte: Gráfico elaborado a partir dos dados das análises de Ribeiro (2010). 
de suas famílias/domicílios, como: arranjos familiares, renda per capita da família, escolaridade dos adultos residentes no domicílio e cor. O Gráfico 4 apresenta os principais resultados encontrados ${ }^{15}$.

A partir da estimação de modelos de regressão logística multinível, as análises observaram que, mesmo controlando por características dos indivíduos e do seu domicílio/família, o local de moradia está associado ao risco de vulnerabilidade (tanto de crianças e adolescentes de 4 a 14 anos quanto de jovens de 15 a 24 anos, risco 1 e risco 2). Crianças e adolescentes que moravam em bairros com alta concentração de adultos em condiçóes precárias de inserção no mercado de trabalho (tipo baixo) tinham 28\% mais chances de estarem na situação de risco (fora da escola ou em atraso escolar), e os jovens tinham 30\% mais chances de estarem em situação de risco (não trabalhar, não estudar, nem procurar emprego) se comparados com os residentes em áreas de tipo alto (com alta concentração de adultos trabalhadores de alto status). Os riscos eram $12 \%$ maior para crianças, adolescentes e jovens residentes em bairros do tipo socioespacial médio, se comparados com aqueles residentes em bairros do tipo alto.

Assim, o estudo apresentou evidências de que morar em bairros com maior diversidade da composição social, ou com maior concentração de pessoas que ocupam posiçóes estáveis e protegidas na hierarquia sócio-ocupacional, parece ser um fator de proteção para as situaçóes de vulnerabilidade. Por outro lado, morar em áreas com grande concentraçáo de pessoas com laços frágeis com o mercado de trabalho parece estar associado ao aumento do risco de estar em situação de vulnerabilidade. Ribeiro (2010) propóe, como hipótese, que o fator de proteção ou de risco poderia ser decorrente tanto de mecanismos de socialização (jovens e crianças mais ou menos expostos a modelos exitosos de papel social) como também de mecanismos instrumentais (maior ou menor acúmulo de capital social na vizinhança, distância/mobilidade urbana, violência). No entanto, o autor argumenta que tais mecanismos precisariam ser investigados em estudos futuros.

A exploração desses mecanismos é aprofundada a partir de estudos realizados nas regióes metropolitanas do Rio de Janeiro e de Belo Horizonte, que buscaram observar o impacto não somente da vizinhança como de condições de moradia sobre o risco de estar em situação de defasagem idade-série (KOSLINSKI et al., 2015; BOGUTCHI; RIGOTTI, 2015)

O estudo de Koslinski et al. (2015) caracteriza o bairro/vizinhança a partir de um indicador similar àquele utilizado por Ribeiro (2010): porcentagem de chefes de família em cada área de ponderação do IBGE que apresentam fragilidade de inserção no mercado de trabalho ${ }^{16}$. No entanto, $o$ indicador não foi classificado a partir de uma tipologia sócio-ocupacional e foi utilizado como variável contínua.

As análises incluíram, além de variáveis relacionadas às características das crianças e adolescentes (sexo e cor) e de suas famílias/domicílios (escolari- 
dade do chefe do domicílio, renda domiciliar per capita), variáveis relacionadas à presença de carências/privaçôes habitacionais. Assim, o estudo buscou investigar a hipótese apresentada por Kaztman (2011) de que as condiçóes de habitação não adequadas poderiam exercer impacto sobre o sucesso e/ou trajetória escolar de crianças e adolescentes. Três características relacionadas às condiçốes de habitação foram foco do estudo, quais sejam: adensamento do domicilio ${ }^{17}$, inadequação do abastecimento de água ${ }^{18}$, inadequação do serviço de coleta de esgoto ${ }^{19}$.

\section{Gráfico 5}

Fatores de risco para defasagem idade-série de um ou mais anos para $4^{\mathrm{a}}$ série $/ 5^{\circ}$ ano e $8^{\mathrm{a}}$ série $/ 9^{\circ}$ ano do ensino fundamental.

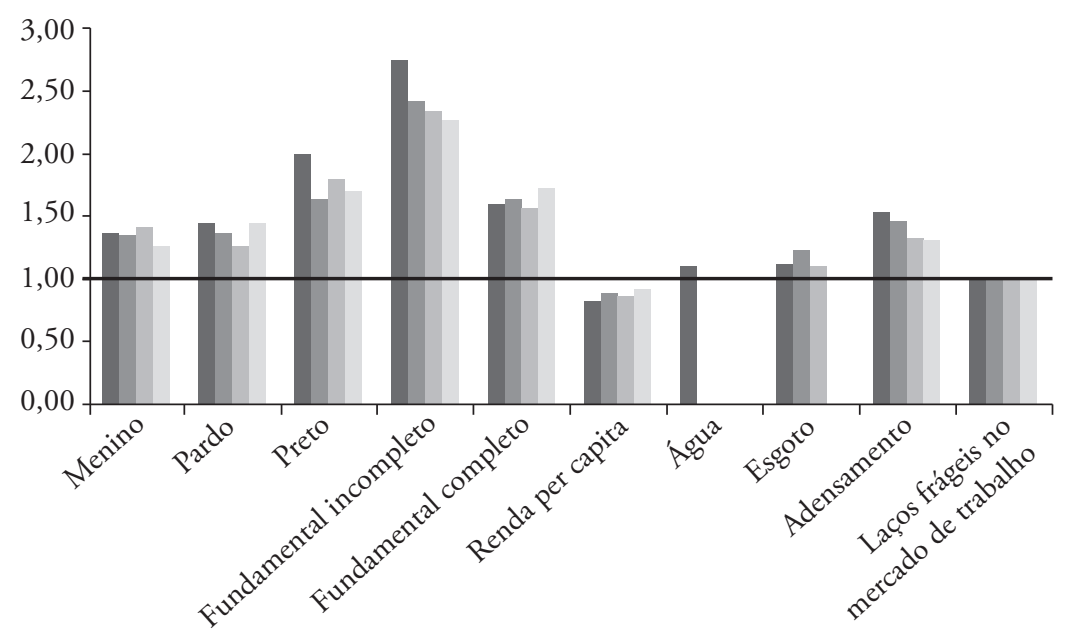

Distorção idade-série 5o ano 2000 Distorção idade-série 9oano 2000

Distorção idade-série 5o ano 2010 Distorção idade-série 9o ano 2010

As categorias "menina", "branco", "ensino médio completo ou ensino superior" foram as categorias de referência para as variáveis sexo, cor e escolaridade do chefe do domicilio, respectivamente. O gráfico apresenta as razöes

de chance (odd ratios) associadas a cada uma das varáveis independentes inseridas no modelo final das regressöes logísticas multinivel, estimando o risco de defasagem idade-série. Os gráficos apresentam resultados somente para os coeficientes estimados pelas regressöes que apresentaram significância estatística $(p \leq 0,10)$.

Fonte: Elaboração a partir das análises apresentados em Koslinski et al. (2015).

Novamente, as análises utilizaram modelos de regressão logística multinível, com dados do Censo demográfico de 2000 e de 2010, para estimar o risco de distorção idade-série para alunos que frequentavam a $4^{\mathrm{a}}$ série $/ 5^{\circ}$ ano e a $8^{a}$ série $/ 9^{\circ}$ ano do ensino fundamental. O Gráfico 5 apresenta os principais resultados das análises ${ }^{20}$.

Os modelos estimaram que, mesmo controlando por características dos indivíduos e de suas famílias e do bairro em que residem, a inadequação da 
condição de moradia é fator de risco de distorção idade-série. Por exemplo, controlando por outras variáveis, alunos em domicílios com serviço inadequado de esgotamento sanitário tinham 12,1 e 23,1\% mais chances de estar em situação de distorção idade-série no $5^{\circ}$ ano em 2000 e 2010, respectivamente, se comparados com alunos em domicílios com serviço adequado. Essa porcentagem era de 9,4\% para o risco de distorção idade-série no $9^{\circ}$ ano em $2000^{21}$.

$\mathrm{O}$ adensamento domiciliar foi a característica da privação habitacional mais fortemente relacionada com o risco de distorção idade-série. Alunos que residiam em situação de densidade domiciliar inadequada (mais de três pessoas por dormitório) tinham em torno de 50\% mais chances de estar em situação de distorção idade-série em 2000 e 2010, se comparados com alunos que residiam em domicílios sem essa privação de habitação. $\mathrm{O}$ risco de distorção idade-série era em torno de $30 \%$ mais elevado para alunos de $9^{\circ}$ ano que residiam em domicílios com alta densidade, se comparados com aqueles que residiam em domicílios com densidade adequada ${ }^{22}$.

O estudo realizado na regiáo metropolitana de Belo Horizonte, utilizando dados do Censo de 2010 e modelos que se aproximam do estudo acima descrito, observou resultados semelhantes: a inadequação da densidade dos domicílios foi um fator que contribuiu para o risco de distorção idade-série para alunos de $5^{\circ}$ e $9^{\circ}$ anos do ensino fundamental e para o abandono escolar. Já as variáveis referentes à inadequação dos serviços de abastecimento de água e de esgoto apresentaram coeficientes estatisticamente significativos somente em alguns dos modelos estimados.

As variáveis relacionadas às condições da moradia presentes nas análises acima descritas foram medidas no nível do domicílio e não do bairro. No entanto, condiçóes de habitação, como a densidade do domicílio, refletem também processos de estruturação urbana e formas de acessar moradia. Além disso, como mencionamos anteriormente, análises realizadas pelo Observatório das Metrópoles indicaram que o Índice de Bem-Estar Urbano (IBEU) e, em especial, as dimensões 3 (condições habitacionais urbanas) e 4 (atendimento de serviços coletivos ${ }^{23}$ ) do índice não estão distribuídas de forma uniforme entre as metrópoles e dentro de cada regiáo metropolitana. O mapeamento dos resultados do IBEU e de suas dimensōes para as áreas de ponderação evidencia uma distribuição que acompanha os padróes da segregação/segmentação residencial das metrópoles ${ }^{24}$ (RIBEIRO; RIBEIRO, 2013a).

Assim, as evidências trazidas a partir dos estudos de Koslinski et al. (2015) e Bogutchi e Rigotti (2015) fortalecem, de um lado, a hipótese de que, além de mecanismos de socialização, mecanismos instrumentais (acesso a serviços coletivos básicos e condiçôes de moradia) podem explicar a relação entre segregação residencial e desigualdades educacionais. Tal relação reforça a necessidade 
de pensar políticas educacionais em articulação com outros setores, como, por exemplo, políticas habitacionais.

Por fim, outros trabalhos com foco no município do Rio de Janeiro observaram que características da vizinhança estão associadas ao desempenho de alunos do ensino fundamental (RIBEIRO; KOSLINSKI, 2010) e, ainda, à disposição desigual dos equipamentos escolares (KOSLINSKI; ALVES; LANGE, 2013).

O estudo de Ribeiro e Koslinski (2010) investigou a associação do padrão de segregaçáo da cidade do Rio de Janeiro em macro e microescalas sobre o desempenho de alunos de $4^{\mathrm{a}}$ e $8^{\mathrm{a}}$ séries do ensino fundamental em testes de matemática. Para tanto, utilizaram dados do censo demográfico (IBGE, 2000) e técnicas de geocodificaçáo e de geoprocessamento para caracterizar a vizinhança e o entorno em que as escolas estavam localizadas. Nesse estudo, as características do entorno das escolas foram medidas a partir da variável clima educativo que indicava a distribuição de adultos com ensino fundamental incompleto, ensino fundamental completo, ensino médio e ensino superior, em cada área de ponderação do IBGE. Além disso, o entorno da escola foi caracterizado de acordo com sua proximidade a áreas de favela, a partir de uma variável que indicava se a escola estava localizada dentro ou até $100 \mathrm{~m}$ de uma favela.

As variáveis referentes às características dos alunos (cor, sexo, trajetória escolar) e de suas famílias (nível socioeconômico), bem como das escolas que frequentam (infraestrutura da escola e composição do alunado), foram elaboradas a partir de dados da Prova Brasil (INEP, 2005) e do Censo Escolar (INEP, 2005). Modelos de regressão linear multinível foram utilizados para estimar a proficiência dos alunos nos testes de matemática da Prova Brasil 2005 para alunos de $4^{\mathrm{a}} \mathrm{e}$ $8^{a}$ séries do município do Rio de Janeiro. A partir do controle por características dos alunos e das escolas que frequentam, foram observadas desvantagens para alunos que estudam em áreas de baixo clima educativo. Por exemplo, alunos de $8^{a}$ série que frequentavam escolas localizadas em áreas de ponderação com concentração de adultos com baixa escolaridade tinham, em média, uma redução de 11 pontos na proficiência de matemática na escala do SAEB se comparados com alunos que frequentavam escolas localizadas em áreas com concentração de adultos com alta escolaridade (clima educativo alto). Essa redução era de 7,9 pontos para alunos matriculados em escolas localizadas em áreas de clima educativo médio.

As análises na microescala da cidade, que consideraram somente escolas que estavam localizadas em áreas de alto clima educativo (com maior concentração de adultos com alta escolaridade), mostraram uma redução de 10,27 pontos na média em matemática para alunos de $8^{a}$ série que estudam em escolas dentro ou muito próximas a áreas de favela. As análises na macroescala indicaram que alunos que frequentavam escolas localizadas em áreas menos abastadas da cidade ou em entornos menos privilegiados obtinham desempenho mais baixo. No en- 
tanto, a vantagem de estudar em escolas nas áreas mais abastadas da cidade não era distribuída de forma uniforme, ou seja, não beneficiava a todos os alunos, uma vez que alunos que estudam em escolas dentro ou muito próximas a áreas de favela tinham em média desempenho mais baixo.

$\mathrm{O}$ artigo propóe que os efeitos tanto relacionados à configuração centro-periferia da cidade, como referentes à distinção favela/asfalto nas áreas mais abastadas da cidade, podem ser interpretados a partir da hipótese dos padróes de sociabilidade ou de isolamento social decorrentes dos padróes de segregação residencial. No entanto, para além da hipótese acerca dos mecanismos de socialização, o artigo propóe explicaçóes que se aproximam dos mecanismos instrumentais: a oferta das escolas apresentaria grande variação no que diz respeito à infraestrutura das escolas, ao clima escolar e/ou a composição do alunado. Esses fatores explicariam, ao menos em parte, as diferenças dos resultados escolares que acompanhavam os padróes de segregação residencial da cidade do Rio de Janeiro.

Essa hipótese foi mais bem investigada tanto por trabalhos mais abrangentes, que buscaram identificar desigualdades na distribuição de recursos escolares na cidade, como por estudos qualitativos que investigaram de forma mais aprofundada os mecanismos a partir dos quais tanto o modelo centro-periferia quanto o modelo de proximidade física e distância social, característicos da segregação da cidade do Rio de Janeiro, afetam a demanda e a oferta escolar.

Alguns estudos realizados no projeto Observatório Educação e Cidade buscaram identificar a distribuição de oportunidades educacionais no município do Rio de Janeiro. Para tanto, Alves, Lange e Bonamino (2010) construíram o Índice de Oportunidades Educacionais, que combina duas dimensóes: demanda de crianças de 6 a 14 anos (com dados do Censo IBGE) e oferta de escolas com ensino fundamental (dados do Censo Escolar/INEP). O estudo mostrou que, em grande parte da cidade, as oportunidades educacionais se caracterizam por uma relação de estabilidade entre demanda e oferta. As áreas que apresentam um baixo padrão de demanda e oferta são aquelas com crescimento urbano mais recente. Por outro lado, as áreas que apresentam oportunidades educacionais mais limitadas (alta demanda e baixa oferta) estão nas favelas cariocas. Diante do contexto de estratificação residencial e educacional no Rio de Janeiro, dados como esse são um importante indicador para o planejamento de ações políticas.

Se o trabalho de Alves, Lange e Bonamino (2010) se concentrou na distribuição dos equipamentos escolares públicos e privados no município do Rio de Janeiro, Koslinski; Alves; Lange (2013) buscaram captar os padróes de desigualdade da distribuição da qualidade dos equipamentos escolares a partir de indicadores relacionados ao contexto social dos alunos, condiçóes de infraestrutura e funcionamento da escola, expectativa docente e resultados escolares. Dessa forma, os autores buscaram identificar mecanismos instrumentais que explicam como a segregação residencial e características da vizinhança 
poderiam limitar a agência dos indivíduos, como a escolha de estabelecimentos escolares.

O estudo, a partir de técnicas de geoprocessamento, observou uma distribuição desigual de escolas públicas de qualidade que acompanha certas características do modelo carioca de segregação residencial. Essa distribuição, conjugada com a oferta desigual de transporte público e acesso à mobilidade urbana, teria importante impacto nas desigualdades de oportunidades educacionais, em especial na cidade do Rio de Janeiro, em que as regras de matrícula no ensino fundamental da rede municipal permitem a escolha de estabelecimentos escolares pelos responsáveis dos alunos. Assim, a dimensão da segregação caracterizada por distância física e social (modelo centro-periferia) representaria barreiras para alunos de periferia acessarem escolas de maior qualidade.

No entanto, mesmo os alunos que moram em favelas localizadas nas áreas mais abastadas da cidade - áreas características do modelo de segregação de proximidade física e distância social — não necessariamente usufruiriam do fato de essas áreas terem maior oferta de escolas de qualidade. O estudo de Costa et al. (2013) estimou fatores associados ao acesso e permanência em escolas com distintos prestígio e desempenho, e observou que alunos que residiam em favelas tinham menor probabilidade de acessar escolas de alto prestígio. Esses alunos também apresentavam maior probabilidade de permanecer em escolas de baixo prestígio, se comparados com alunos de origem similar não residentes em áreas de favela. Os autores propóem como hipótese explicativa para essa desigualdade de acesso uma possível seleçáo realizada pelas escolas que levariam em conta, entre outros fatores, o local de moradia dos alunos.

Os estudos com desenhos qualitativos investigaram de forma mais aprofundada mecanismos que nos permitem compreender a relação entre características do bairro/vizinhança e as desigualdades educacionais. No entanto, esses esforços foram realizados principalmente na cidade do Rio de Janeiro, que, como vimos anteriormente, apresenta um modelo de segregação residencial que somente parcialmente é caracterizado pelo modelo centro-periferia.

Em geral, os estudos focalizaram mecanismos instrumentais do efeito vizinhança. Por exemplo, observaram representaçóes negativas das favelas e estigma por parte dos professores em relação às crianças moradoras da favela. Essas relaçôes foram percebidas tanto em escolas próximas às favelas localizadas em entornos mais abastados (CHRISTOVÃO; SANTOS, 2010) como em escolas localizadas em favelas em áreas mais periféricas da cidade (ALBUQUERQUE, 2014).

Outros estudos identificaram como as redes sociais que famílias moradoras de favelas estabeleciam nas vizinhanças estavam associadas a suas estratégias de escolha e de acesso a estabelecimentos escolares (ZUCCARELLI, 2009, NOVAES, 2010). Tais estudos pesquisaram famílias que escolhiam matricular seus filhos em escolas localizadas nas favelas ou próximas às favelas onde residiam e famílias que 
optavam por escolas de maior prestígio e mais distantes. Zuccarelli (2009) e Novaes (2010) observaram que as famílias não eram igualmente afetadas pelo isolamento social: mesmo com perfis socioeconômicos semelhantes e residindo na mesma vizinhança, acessavam diferentes redes sociais em que circulavam informaçóes sobre o prestígio das escolas. Além disso, as famílias que optavam por escolas de maior prestígio e mais distantes da favela apresentavam motivaçóes que incluíam desde evitar o contato/socialização com pessoas que viviam na vizinhança até percepçóes negativas sobre a qualidade das escolas localizadas nas favelas.

No entanto, os estudos acima mencionados exploraram pouco os mecanismos de socialização da vizinhança e suas relações com oportunidades escolares. Além disso, os estudos que buscaram compreender o funcionamento de mecanismos institucionais focalizaram o funcionamento das escolas e pouco se ativeram a aspectos relacionados à privação de acesso a outros equipamentos ou serviços coletivos, como as carências habitacionais, serviços de saneamento, coleta de lixo, mobilidade urbana, etc. Por fim, outra lacuna é a ausência de estudos comparativos capazes de captar as semelhanças e diferenças do funcionamento dos mecanismos da segregação residencial e de isolamento social nos diferentes contextos de segregação: proximidade física e distância social X distância física e distância social. Por exemplo, indivíduos residentes em vizinhanças caracterizadas por essas diferentes dimensóes de segregação residencial teriam acesso desigual à mobilidade urbana, a opçóes de escolha de estabelecimentos escolares (em especial de escolas de alto prestígio/qualidade) e a outros equipamentos públicos e serviços coletivos. Essas comparaçôes permitiriam uma melhor compreensão de como o acesso ao bem-estar urbano em diferentes regióes da cidade afetam os resultados e trajetórias escolares.

\section{À guisa de conclusão: implicações para as políticas de educação}

A experiência de pesquisa relatada neste artigo tem gerado a reflexão sobre a imperiosa necessidade de transformar o modelo de políticas públicas que preside historicamente a intervenção pública na provisão de serviços públicos. Com efeito, o seu caráter essencialmente setorial fundamenta-se em um modo de pensar a questão social e um regime fragmentado de ação das agências públicas, ao nosso ver, totalmente incompatível com o caráter crescentemente totalizador das necessidades de bem-estar e da efetiva democratização das oportunidades, decorrente do nosso ingresso no estágio histórico de sociedade urbana previsto por Lefebvre (1999) e cuja expressão mais forte é o fenômeno metropolitano. Este se expressa pela constituição de um espaço social de natureza distinta do constituído pela cidade comum, na medida em que a reprodução da cidade nas dimensóes biológica e social, individual e coletiva é altamente dependente de um 
meio ambiente construído, que conforma um fundamental substrato material de todos os fatos sociais.

Como argumentamos anteriormente, as oportunidades educacionais são condicionadas pelas práticas de interação social que ocorre no âmbito da família, da escola e da comunidade (bairro). Assim, a eficácia e a equidade do funcionamento da escola dependem, entre outros fatores, da qualidade e da isonomia do ambiente provido pelo espaço social da metrópole. Torna-se imperioso, sob esse ponto de vista, que ocorra a articulação das açóes públicas concernidas nesta relação. Tal seria possível pela incorporação da dimensão territorial na política educacional e, ao mesmo tempo, pela consideração da dimensão oportunidade nas políticas urbanas. É necessário, para tanto, que os projetistas dessas políticas considerem, por um lado, que a promoçáo da educação náo ocorre apenas no âmbito da escola e que, por outro lado, o planejamento da cidade não pode apenas considerar a provisão de serviços urbanos.

\section{Notas}

1. O Observatório das Metrópoles é um instituto de pesquisa em rede que realiza pesquisas sobre diversos temas relacionados aos desafios e tendências convergentes e divergentes entre as metrópoles, geradas pelos efeitos das transformaçôes econômicas, sociais, institucionais e tecnológicas por que passa a sociedade brasileira nos últimos 20 anos. As Instituiçôes reunidas hoje no Observatório das Metrópoles realizam pesquisas focalizando 14 metrópoles e uma aglomeração urbana: Rio de Janeiro, São Paulo, Porto Alegre, Belo Horizonte, Curitiba, Goiânia, Recife, Salvador, Natal, Fortaleza, Belém, Santos, Vitória, Brasília e a aglomeração urbana de Maringá. Para maiores informaçôes ver: http://www.observatoriodasmetropoles.net/.

2. O projeto agregou pesquisadores do Observatório das Metrópoles (Instituto de Pesquisa e Planejamento Urbano e Regional - IPPUR/UFRJ), do Laboratório de Avaliação da Educação (Faculdade de Educação da PUC-Rio), do Instituto de Filosofia e Ciências Sociais (Programa de pós-graduação em Sociologia e Antropologia - IFCS/UFRJ) e do Instituto de Filosofia e Ciências Humanas (Programa de pós-graduação em Ciências Sociais -IFCH/UERJ). O projeto contou com financiamento do Edital Observatório da Educação (nº 001/2006/INEP/CAPES).

3. O segundo projeto, Observatório Educação e Cidade, além de pesquisadores das instituiçóes anteriormente mencionadas, contou com a participação de pesquisadores do Laboratório de Pesquisa em Oportunidades Educacionais (LaPOpE/Faculdade de Educação/UFRJ) e, novamente, com o financiamento do Edital Observatório da Educação (edital nº 38/2010/CAPES/INEP).

4. Regimes de bem-estar social: modo pelo qual o bem-estar social é assegurado por meio de três esferas: família/comunidade; mercado; estado. De acordo com Ribeiro, "nas metrópoles brasileiras, a vulnerabilidade social decorre da crise de um regime de bem-estar social dual, fundado a partir da combinação das livres forças de mercado e da mobilização das estruturas familiar-comunitárias, particularidades do nosso desenvolvimento capitalista" (RIBEIRO, 2010, p.221). 
5. De acordo com Wilson (1987), o isolamento social priva náo somente de recursos sociais e econômicos — incluindo modelos convencionais de referência - mas também de aprendizado cultural a partir de redes sociais mais tradicionais que facilitaria a mobilidade econômica e social nas sociedades modernas. É característico do ambiente social do que chamou de underclass, termo que indica posição desvantajosa no mercado de trabalho e ambiente social de pobreza concentrada e isolamento social.

6. Katzman (2001) define como ativos: o capital social individual referido à capacidade que uma pessoa tem de mobilizar a vontade de outras pessoas em seu benefício; o capital social coletivo que se refere à capacidade que tem de mobilizar as vontades de muitos na direção de uma meta coletiva; e o capital cívico referido à capacidade que tem de sentir e de compartilhar problemas e destinos de outras pessoas.

7. O IBEU foi calculado para os 15 grandes aglomerados urbanos e contém 5 dimensốes: mobilidade urbana; condiçôes ambientais urbanas; condiçóes habitacionais urbanas; atendimento de serviços coletivos urbanos; infraestrutura urbana. Cada uma das dimensôes do IBEU é constituída por um conjunto de indicadores construídos a partir do censo demográfico do IBGE de 2010. O índice não permite comparação ao longo do tempo uma vez que alguns de seus indicadores não estão presentes nos questionários do Censo de 2000. Para saber mais, ver Ribeiro; Ribeiro (2013a).

8. Para uma discussão mais aprofundada sobre a análise social do território, ver Ribeiro e Ribeiro (2013b). Para uma descrição mais detalhada sobre as categorias sócio-ocupacionais, ver Ribeiro e Chetry (2015).

9. Para uma discussão mais detalhada sobre a relação entre redes sociais/capital social, escolha de estabelecimentos escolares e desigualdades de oportunidades educacionais, ver Zuccarelli (2009), Nogueira (1998) e Moreira (2014).

10. As análises realizadas compreendem dados de 15 metrópoles que, de acordo com estudo anterior realizado pelo Observatório das Metrópoles (2009), são aglomerados urbanos que exercem funçôes metropolitanas na rede urbana brasileira, quais sejam: Belém, Belo Horizonte, Brasília, Campinas, Curitiba, Florianópolis, Fortaleza, Goiânia, Manaus, Porto Alegre, Recife, Rio de Janeiro, Salvador, São Paulo e Vitória.

11. As análises realizadas utilizaram os microdados do Censo demográfico (IBGE, 2000).

12. O estudo utilizou a técnica de classificação hierárquica ascendente para criar as três posiçôes.

13. O indicador de integração dos municípios às regióes metropolitanas é composto pelas seguintes dimensôes: crescimento populacional, densidade demográfica, contingente e proporção de pessoas que realizam movimento pendular, proporçáo de emprego não agrícola, PIB, presença de portos e aeroportos.

14. O indicador de fragilidade de laços com o mercado de trabalho agregou as seguintes situaçóes: (i) desempregado; (ii) trabalhador por conta própria de baixa qualificação; (iii) trabalhador de baixa qualificação sem carteira assinada com renda inferior a dois salários-mínimos; (iv) trabalhador doméstico sem carteira assinada; (v) trabalhador doméstico com carteira assinada e com renda inferior a dois salários-mínimos; (vi) empregador de baixa qualificação com carteira assinada e com renda 
inferior a dois salários-mínimos; (vii) trabalhador na produção para o próprio consumo e aprendiz ou estagiário sem remuneração.

15. Os domicílios com mais de três pessoas por dormitório foram considerados como inadequados ou com adensamento domiciliar.

16. Somente a categoria rede geral de distribuiçáo foi considerada como atendimento adequado do serviço de abastecimento de água.

17. Somente a categoria rede geral de esgoto ou pluvial foi considerada como atendimento adequado de serviço de esgoto.

16. Nos modelos que estimaram a distorção idade-série para o $9^{\circ}$ ano em 2010 , a variável adequação do serviço de esgoto não apresentou coeficientes estatisticamente significativos.

17. A variável referente à adequação do abastecimento de água só apresentou um impacto pequeno e estatisticamente significativo para os modelos que estimaram o risco de distorção idade-série no $5^{\circ}$ ano em 2000.

18. A dimensão 3 do IBEU compreende a variável adensamento domiciliar, e a dimensão 4 compreende as variáveis atendimento adequado de esgoto e atendimento adequado de água.

19. Por exemplo, os mapeamentos realizados mostram que as condiçóes de habitação na regiáo metropolitana do Rio de Janeiro são mais precárias em algumas áreas periféricas e em áreas caracterizadas como aglomerados subnormais, ou áreas de favela (Ribeiro; Ribeiro, 2013a).

\section{Referências}

ALBUQUERQUE, R.L.F. de. Segregação residencial, estratificaçâo escolar e desigualdades de oportunidades: um estudo sobre as percepçóes e práticas docentes no ambiente escolar de educandos da Maré. Dissertação (Mestrado em Educação). Programa de Pós-Graduação em Educação, Universidade Federal do Rio de Janeiro, Rio de Janeiro, 2014.

ALVES, F.; LANGE, W.; BONAMINO, A. A geografia objetiva de oportunidades educacionais na cidade do Rio de Janeiro. In: RIBEIRO, L.C.Q. et al. (Org.). Desigualdades Urbanas, Desigualdades Escolares. Rio de Janeiro: Letra Capital, 2010. p. 67-89.

BOGUTCHI, T.; RIGOTTI, J.I.R. Rendimento escolar e desigualdades socioespaciais na RMBH. In: ANDRADE, L.T.; MENDONÇA, J.G.; DINIZ, A.M.A. (Ed.) Belo Horizonte: transformaçóes na ordem urbana. Rio de Janeiro: Letra Capital/Observatório das Metrópoles/Belo Horizonte, MG/PUC-Minas, 2015.

CHRISTOVÃO, A.C.; SANTOS, M.M.A Escola na Favela ou a Favela na Escola? In: RIBEIRO, L.C.Q. et al. (Org.). Desigualdades Urbanas, Desigualdades Escolares. Rio de Janeiro: Letra Capital: Observatório das Metrópoles: IPPUR/ UFRJ, 2010, p. 277-297.

COSTA, M.; KOSLINSKI, M.C.; ALVES, F.; RIBEIRO, L.C.Q. Quase-mercado escolar em contexto de proximidade espacial e distância social: o caso do Rio de Janeiro. In: VIEIRA, M.M. et al. (Org.). Habitar a escola e suas margens: geografias plurais em confronto. 
1ed. Porto Alegre: Instituto Politécnico de Portalegre - Escola Superior de Educação, 2013, p. 37-47.

ELLEN, I.G.; TURNER, M.A. Does Neighborhood Matter? Housing Policy Debate, v. 8, issue 4. Fannie Mae Foundation, 1997.

JENCKS, C.; MAYER, S. The social consequences of growing in a poor neighborhood. In: LYNN, L.E., MCGEARY, M.G.H. (Eds.). Inner-citypoverty in the United States. Washington, DC: National Academy, 1990. p. 111-186.

KAZTMAN, R. Seducidos y abandonados: El aislamiento social de los pobres urbanos. Revista de CEPAL, n. 75, diciembre de 2001.

Infancia en América Latina: privaciones habitacionales y desarrollo de capital humano. Documentos de proyectos CEPAL, 2011.

KOSLINSKI, M.C.; ALVES, F; HEREDIA, P.Y.; REGIS, A. Segregação residencial, moradia e desigualdade escolar. In: RIBEIRO, L.C.Q. (Ed.) Rio de Janeiro: transformaçóes na ordem urbana. Rio de Janeiro: Letra Capital/Observatório das Metrópoles, 2015.

KOSLINSKI, M.C.; ALVES, F.; LANGE, W. Desigualdades Educacionais em Contextos Urbanos: Um estudo sobre geografia de oportunidades educacionais na cidade do Rio de Janeiro. Educaçâo \& Sociedade, Campinas, v. 34, n. 125, p. 1175-1201, out-dez, 2013.

LEFEBVRE, H. A revolução urbana. Belo Horizonte: Editora UFMG, 1999.

MOREIRA, A.M. Estratégias familiares e oportunidades educacionais na rede pública do município do Rio de Janeiro. Dissertação (Mestrado em Educação). Programa de PósGraduação em Educação, Universidade Federal do Rio de Janeiro, Rio de Janeiro, 2014.

NOGUEIRA, M.A.A. Escolha do estabelecimento de ensino pelas famílias: a ação discreta da riqueza cultural. Revista Brasileira de Educação, São Paulo, v. 1, n. 7, p. 42-56, jan/fev/ mar/abr, 1998.

NOVAES, P.R. Valor social da educação e efeito vizinhança: uma análise das famílias moradoras da Rocinha. Dissertaçáo (Mestrado em Planejamento Urbano e Regional). Instituto de Pesquisa e Planejamento Urbano e Regional, Universidade Federal do Rio de Janeiro, Rio de Janeiro, 2010.

OBSERVATÓRIO DAS METRÓPOLES. Hierarquização e identificação dos espaços urbanos. Coleção Conjuntura Urbana. Rio de Janeiro: Letra Capital/Observatório das Metrópoles, 2009.

RIBEIRO, L.C.Q. Segregação residencial e políticas públicas: análise do espaço social da cidade na gestão do território. In: Saúde nos Grandes Aglomerados Urbanos: uma visão integrada, Projeto de Desenvolvimento de Sistemas e Serviços de Saúde, OPAS/OMS, Brasília, 2003.

Desigualdades de oportunidades e segregação residencial: a metropolização da questão social no Brasil. Revista Caderno CRH, v. 23, n. 59, 2010.

Transformaçôes na Ordem Urbana das Metrópoles Brasileiras: 1980/2010. Hipóteses e estratégia teórico-metodológica para estudo comparativo. Rio de Janeiro: Observatório 
das Metrópoles/Instituto Nacional de Ciência E Tecnologia / FAPERJ - CAPES - CNPq, 2013.

RIBEIRO, M.G.; CHETRY, M. As categorias sócio-ocupacionais e a análise social do território. In: RIBEIRO, L.C.Q (Org.) Rio de Janeiro: transformaçóes na ordem urbana. Rio de Janeiro: Letra Capital, 2015, p. 148-160.

RIBEIRO, L.C.Q., KAZTMAN, R. (Org.). A Cidade Contra a Escola?: segregação urbana e desigualdades educacionais em grandes cidades da América Latina. Rio de Janeiro: Letra Capital, FAPERJ, 2008.

RIBEIRO, L.C.Q.; KOSLINSKI, M.C. Fronteiras Urbanas da Democratização das Oportunidades Educacionais: o caso do Rio de Janeiro. In: RIBEIRO, L.C.Q. et al. (Org.). Desigualdades Urbanas, Desigualdades Escolares. Rio de Janeiro: Letra Capital, 2010, p. 121-153.

RIBEIRO, L.C.Q; RIBEIRO, M.G. (Orgs.) IBEU - Índice de Bem-Estar Urbano. Rio de Janeiro: Letra Capital, 2013a. Análise Social do Território. Rio de Janeiro: Letra Capital, 2013b.

RIBEIRO, L.C.Q.; SOUZA, F.C.; RODRIGUES, J.M. Segregação residencial e emprego nos grandes espaços urbanos brasileiros. Cadernos Metropoles, São Paulo, v. 12, n. 23, p. 15-41, jan/jun 2010.

SMALL, M.L.; NEWMAN, K. Urban Poverty after The Truly Disadvantaged: the rediscovery of the family, the neighborhood, and culture. Annual Review of Sociology, v. 27, p. 23-45, 2001.

WILSON, W.J. The Truly Disavantaged. The University of Chicago Press: Chicago and London, 1987.

ZUCCARELLI, C. Segregação residencial, geografia de oportunidades e desigualdades educacionais no Rio de Janeiro. Dissertaçáo (Mestrado em Planejamento Urbano e Regional). Instituto de Pesquisa e Planejamento Urbano e Regional, Universidade Federal do Rio de Janeiro, Rio de Janeiro, 2009.

Recebido em 26 de novembro de 2015.

Aprovado em 29 de janeiro de 2016. 